\title{
Mineração
}

\section{Estratégia de controle de qualidade de minérios na lavra utilizando simulação geoestatística}

\author{
Fernando Gambin \\ Eng.de Minas, Doutorando do PPGEM, UFRGS.E-mail:gambin@ufrgs.br \\ João Felipe C.L. Costa \\ Eng.de Minas, Prof.Dr.do DEMIN, UFRGS.E-mail: jfelipe@ufrgs.br \\ Jair Carlos Koppe \\ Eng. de Minas, Geólogo, Prof.Dr. do DEMIN, UFRGS.E-mail: jkoppe@ufrgs.br
}

\section{Resumo}

Novas centrais térmicas utilizam carvão ROM (run of mine) na geração de energia termoelétrica. Assim, flutuações de qualidade do carvão serão transferidas da mina para o consumidor final. Contratos entre produtor-consumidor estabelecem limites para parâmetros geológicos e tecnológicos do produto final (minério ROM). O descumprimento dos limites estabelecidos gera penalização e/ou rejeição de lotes de minério. O custo elevado dessas penalizações recomenda o controle de qualidade do minério no produto final. A utilização de técnicas geoestatísticas visa a caracterizar a qualidade e a variabilidade do minério a ser lavrado. Tradicionalmente, essa estratégia utiliza um modelo de blocos gerado por um estimador tradicional, geralmente krigagem ordinária. A estimativa dos blocos por krigagem não considera a incerteza associada ao modelo geológico, não sendo adequada para prever flutuações locais. Diferente da krigagem, os métodos de simulação geoestatística têm como objetivo reproduzir a variabilidade in situ e a continuidade espacial dos dados originais. Uma vez que os teores e sua variabilidade são estimados, flutuações da qualidade do minério podem ser previstas para determinada rota de lavra e certo tamanho de lote entregue ao consumidor. Diferentes tamanhos de lote são testados a fim de obter-se o controle das flutuações da qualidade do minério. Esse procedimento é aplicado em um estudo de caso em mineração subterrânea de carvão no sul do Brasil. A utilização de simulação geoestatística possibilida acessar a incerteza associada à qualidade de determinado volume de minério no depósito.

Palavras-chaves: geostatística, simulação estocástica, carvão, planejamento de lavra.

\begin{abstract}
The new generation of coal fired power plants in Brazil are expected to use ROM coal as fuel. Thus, variations of coal quality tend to be transferred from mine to the final user. Contracts frequently establish max-min limits for geological and technological parameters. Lots of ore with quality beyond the agreed limits can be rejected or penalized. The high costs of these penalties require quality control of the final product(ROM). The utilization of geostatistical methods aims for quality and variability characterization of ore in the deposit. The geostatistical method uses a block model with grades assigned to each block normally by ordinary kriging. This block model ignores or is inappropriate for accessing the uncertainty associated with the geological model. Consequently, this procedure fails in predicting grade fluctuations correctly. Contrary to kriging, simulation methods aim at reproducing in situ grade variability and spatial continuity. Once a block model has each grade uncertainty evaluated, quality fluctuation can be predicted for a given mining route and size of lot delivered to the customer. Different mining routes and sizes of ore lots are tested until a desirable level of grade oscillation is achieved. Results from a case study at a Brazilian coal mine proved the adequacy and functionality of the method. Simulation geostatistical makes possible predictions of quality fluctuations at certain volumes of ore in the deposit.
\end{abstract}

Keywords: Geostatistics, stochastic simulation, coal, mining planning. 


\section{Introdução}

A indústria carbonífera sul-brasileira está em fase de adaptação às novas necessidades de geração de energia elétrica no país. Em face da crise no setor energético e da constante necessidade de redução de custos, na geração de energia, novas centrais térmicas a carvão vem sendo projetadas de modo a maximizar a recuperação do minério, e, para isso, utilizarando carvão ROM (run of mine).

A utilização de carvão ROM como produto final da atividade de mineração possibilita a redução de custos associados ao beneficiamento do minério, restando, nessa etapa, apenas os custos associados à redução granulométrica. Tradicionalmente, variações de parâmetros de qualidade no minério são controladas através do beneficiamento, no entanto, com a comercialização na forma de minério ROM, as flutuações de qualidade verificadas in situ (na jazida) serão transportadas diretamente para o produto final sem a possibilidade de interferência de uma unidade de beneficiamento para regular essas variações.

As usinas termoelétricas se caracterizam por baixa maleabilidade quanto às especificações de qualidade do minério que alimenta o processo. Assim, o controle de parâmetros, como, por exemplo, o teor de cinzas, é essencial para o desempenho adequado da usina. Geralmente, exigências contratuais definem essas especificações de qualidade, sendo determinadas penalidades quando determinada quantidade de minério entregue não possua as características especificadas. Por esse motivo, impõe-se a necessidade de conhecimento da variabilidade in situ de parâmetros-chave para, então, serem utilizadas técnicas que permitam controlar a variabilidade do parâmetro no produto final.

Segundo Schofield (1980), existem três estratégias principais para a homogeneização de minérios a serem lavrados: i) Homogeneização na lavra através da utilização de técnicas geoestatísticas para previsão e controle da variabilidade no carregamento; ii) pilhas de homogeneização e; iii) todos os passos de um processo metalúrgico ou de beneficiamento. Entre as alternativas de homogeneização consideradas, a utilização de pilhas de homogeneização e a utilização de processo de beneficiamento se caracterizam pelos elevados custos de implementação e pela flexibilidade em relação às características do material de alimentação. Complementarmente, a utilização de técnicas geoestatísticas para a previsão da variabilidade do minério apresenta custos de aplicação reduzidos, porém implica a necessidade de um maior conhecimento das características do depósito mineral e de sua variabilidade de teores.

Tradicionalmente, a operação de controle de teores é feita, através da utilização de um modelo de blocos gerado por um estimador tradicional, geralmente krigagem ordinária de blocos, a qual realiza a melhor estimativa (não tendenciosa e com menor erro) a partir das amostras disponíveis. No entanto, esse procedimento é incapaz de incorporar a incerteza associada à estimativa. A variabilidade dos valores estimados é menor que a variabilidade dos dados originais (Costa et al., 1998).

Diferente da krigagem, os métodos de simulação geoestatística têm como objetivo reproduzir a variabilidade, in situ, e a continuidade espacial dos dados originais, pela geração de imagens equiprováveis, condicionadas aos dados, que reproduzem as características estatísticas de $1^{\mathrm{a}}$ e $2^{\mathrm{a}}$ ordem dos dados amostrais. Desse modo, a intensidade de incerteza, associada às estimativas pode, ser avaliada (Goovaerts, 1997). Segundo Journel e Huijbregts (1978), os objetivos da simulação e da estimativa são, normalmente, incompatíveis.

Considerando a realidade da mineração de carvão da região Sul, onde a redução de custos é necessária para garantir a competitividade da energia termoelétrica, esse estudo propõe a utilização de simulação seqüencial Gaussiana na estratégia de homogeneização, de forma a atender a necessidade de predizer as possíveis oscilações na qualidade do minério in situ transportadas para o produto final, garantindo, no futuro, o controle da qualidade desse produto dentro de limites estabelecidos em contrato.

\section{Metodologia}

Os principios básicos de simulação condicional foram apresentados inicialmente em Journel (1974). A idéia básica da simulação seqüencial Gaussiana é acessar a incerteza associada à estimativa, antes mesmo de tentar alguma predição sobre os valores da própria variável. Ao invés de buscar a minimização do erro localmente, os métodos de simulação procuram produzir realizações que honrem as feições globais dos dados originais, como o histograma e a continuidade espacial. A medida da diferença entre várias realizações, que, em média, reproduzem as feições globais dos dados originais, permite quantificar a incerteza da estimativa (Costa, 1997).

O conhecimento das flutuações do teor de cinzas em uma mina de carvão é de grande importância para o planejamento da lavra, especialmente quando o produto final é carvão ROM fornecido para centrais térmicas, observando limites máximos e minimos de teor de cinza (Gambin, 2002). O limite estabelecido pelo projeto da usina para o teor de cinzas no minério fornecido é de $60 \%$ de cinzas, com tolerância de $\pm 3 \%$. Portanto tornase de extrema importância o controle das variações do teor de cinzas in situ para que um determinado volume de minério entregue na usina não sofra multas contratuais.

Um estudo de caso foi realizado em uma mineração subterrânea de carvão localizada no sul do Brasil, na bacia carbonífera de Santa Catarina. Nesse estudo, foram utilizados 239 furos de sonda, contendo a análise do teor de cinzas na camada de carvão existente. A Figura 1 apresenta a localização das amostras utilizadas para o teor de cinzas e a estatística básica para os dados de cinza.

O processo de simulação seqüencial Gaussiana foi realizado com os algoritmos da GSLIB (Deutsch e Journel, 1998). O método de simulação requer os dados em uma distribuição normal, por isso é realizada a transformação Gaussiana dos dados originais. Segundo Goovaerts (1997), a inconveniência da necessidade de que os dados apresentem 
Fernando Gambin et al.

uma distribuição normal é que raramente os dados reais apresentam tal comportamento. Dessa forma, existe a necessidade de se recorrer à transformação dos dados originais para o espaço normal.

A Equação (1) e a Figura 2 apresentam a continuidade espacial da variável teor de cinzas para os dados normalizados. $\mathrm{O}$ fenômeno apresentou maior continuidade na direção N-S.

$\gamma(h)=0,2+\left[0,29 . S h_{(1)}\left[\frac{h N-S}{432}, \frac{h E-W}{369}\right]+0,51 . \operatorname{Sph}_{(2)}\left[\frac{h N-S}{5200}, \frac{h E-W}{1271}\right]\right]$

A rotina sgsim (Deutsch \& Journel, 1998) foi utilizada para a geração de possíveis cenários da variável de trabalho. Para esse estudo, 70 realizações mostraram-se suficientes para mapear a incerteza associada à estimativa do teor de cinzas. As etapas da simulação seqüencial Gaussiana estão implementadas na rotina sgsim.
As simulações são geradas utilizando os dados normalizado resultando valores simulados no espaço normal. A retrotransformação dos dados simulados no espaço normal para o espaço original é realizada utilizando o caminho inverso utilizado na normalização inicial. A Figura 3 apresenta três realizações escolhidas aleatoriamente entre as 70 simulações geradas para o teor de cinzas. A utilização dos modelos simulados requer que os mesmos sejam validados para verificar se reproduzem as características de primeira e segunda ordem dos dados condicionantes. A reprodução das

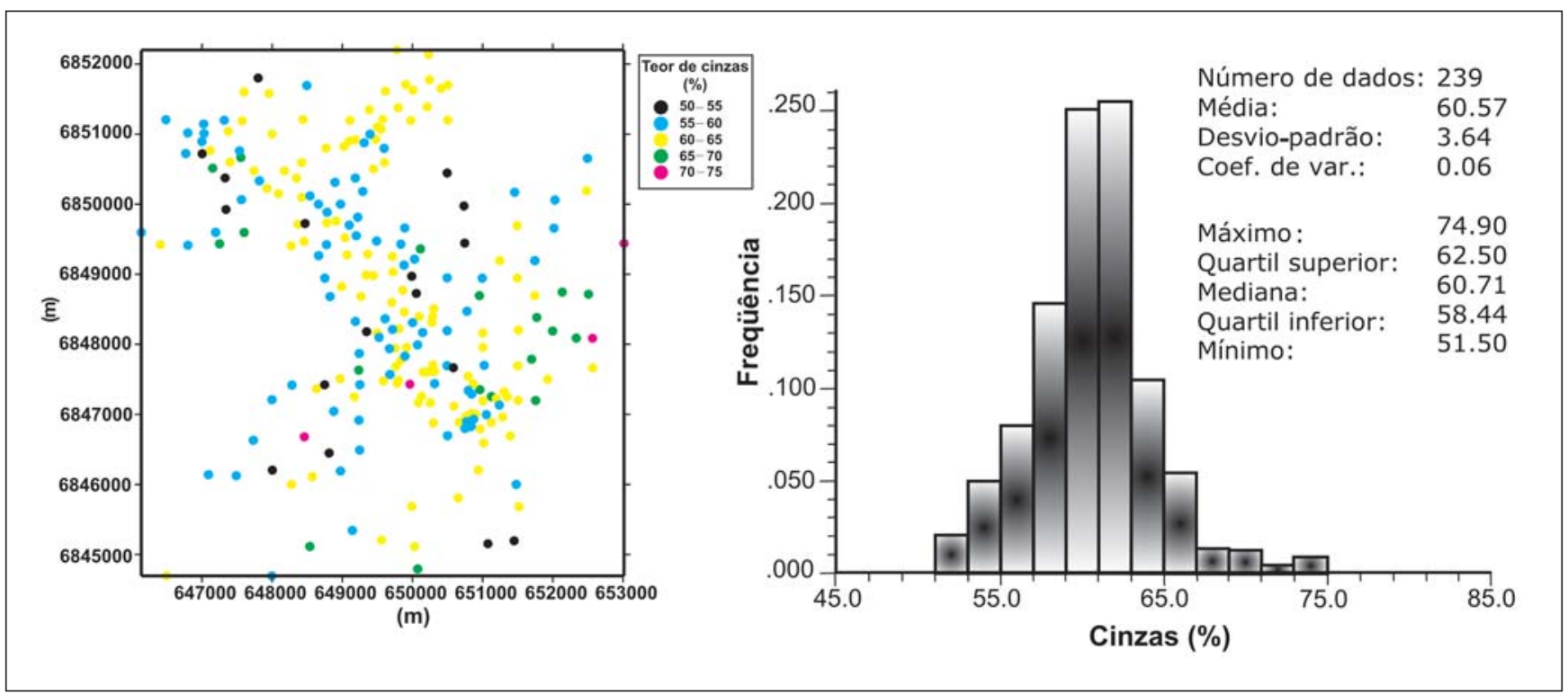

Figura 1 - Localização dos furos de sondagem e estatística básica para os dados de teor de cinzas (\%) na camada de carvão.

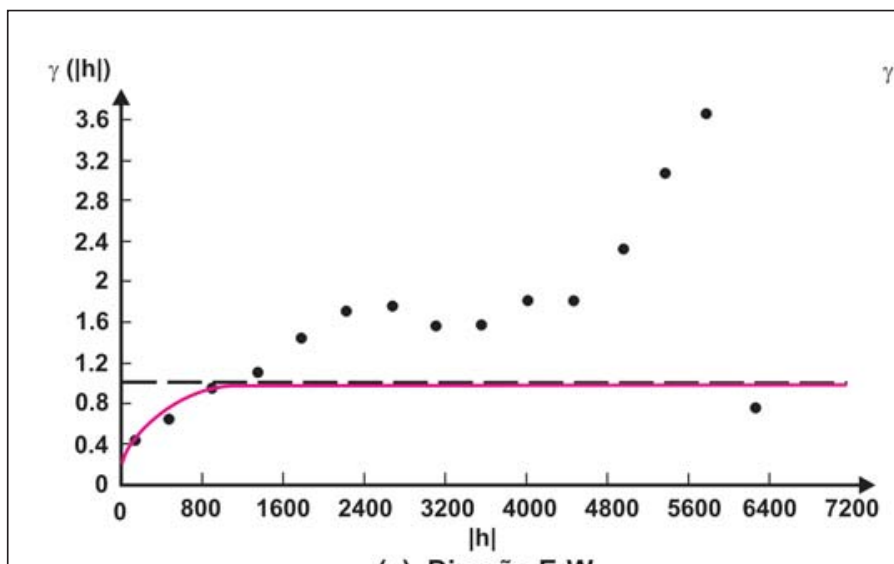

(a) Direção E-W

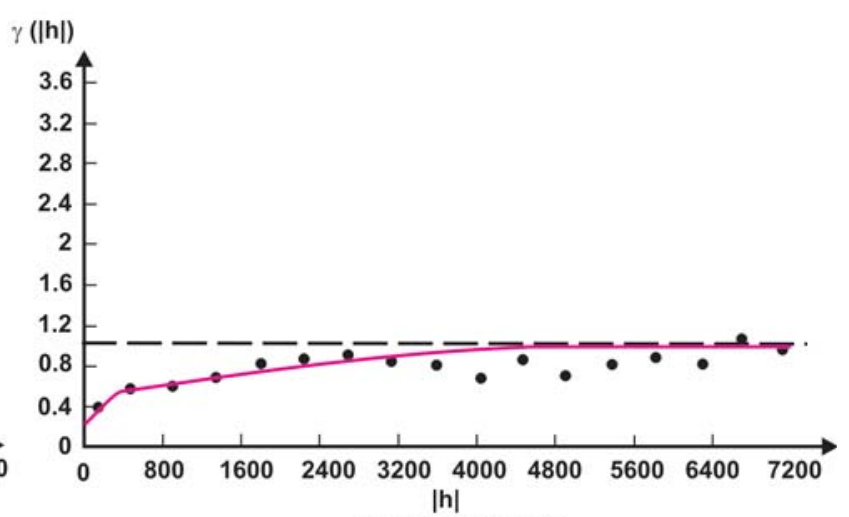

(b) Direção N-S

Figura 2 - Mapeamento da continuidade espacial para os dados normalizados de cinzas. Variograma experimental (pontos) e modelo ajustado (linha contínua) na direção de mínima (E-W) e máxima (N-S) continuidade. 
características de primeira ordem foram verificadas através da análise dos histogramas gerados para os modelos simulados e as características de segunda ordem, através dos variogramas experimentais dos dados simulados.

Os modelos gerados por simulação seqüencial Gaussiana permitem a modelagem da incerteza associada aos valores estimados para o teor de cinzas. Com as 70 simulações geradas e validadas para a variável de estudo, é possível quantificar a variabilidade do teor de cinzas, a fim de que se possam avaliar suas flutuações em determinado bloco ou painel de lavra.

\section{Resultados e discussão}

Os modelos simulados foram utilizados para acessar a incerteza associada ao atributo de interesse teor de cinzas em um projeto de lavra subterrânea de carvão. O pós-processamento dos modelos foi realizado visando a incorporar a incerteza no controle das caracteristicas do minério em determinado volume, aqui denominados lote de minério ROM. Então, foram analisados diferentes tamanhos de lotes associados à capacidade produtiva da lavra de forma a manter o produto final dentro de especificações estabelecidas.

Para incorporar a incerteza proporcionada pelos modelos simulados no planejamento de lavra, foram selecionados, entre os 70 cenários gerados aqueles que representam, para o teor de cinzas, a menor média, maior média, mediana, quartil inferior e quartil superior. Além desses cinco cenários, utilizou-se um modelo gerado pela média dos setenta valores simulados para cada bloco (E-TYPE). Esse modelo tende a ser semelhante a um modelo obtido por krigagem ordinária, apresentando o mesmo efeito suavizador verificado em um mapa gerado por krigagem. Sobre cada um dos modelos selecionados, foi analisado o planejamento da lavra de forma a prever as características de um lote de minério extraído com o processo de lavra. Para cada um dos cenários, haverá uma resposta diferente para o teor de cinzas em um lote.

O lote pode ser definido como sendo uma quantidade definida de minério a ser entregue ao consumidor final e que sofrerá uma caracterização qualitativa, mais especificamente do teor de cinzas. Com base na relação variância x volume, é definido um tamanho de lote que controle as flutuações dos teores de cinzas para os possíveis cenários selecionados. O tamanho desse lote está relacionado à quantidade de minério a ser lavrado em determinada

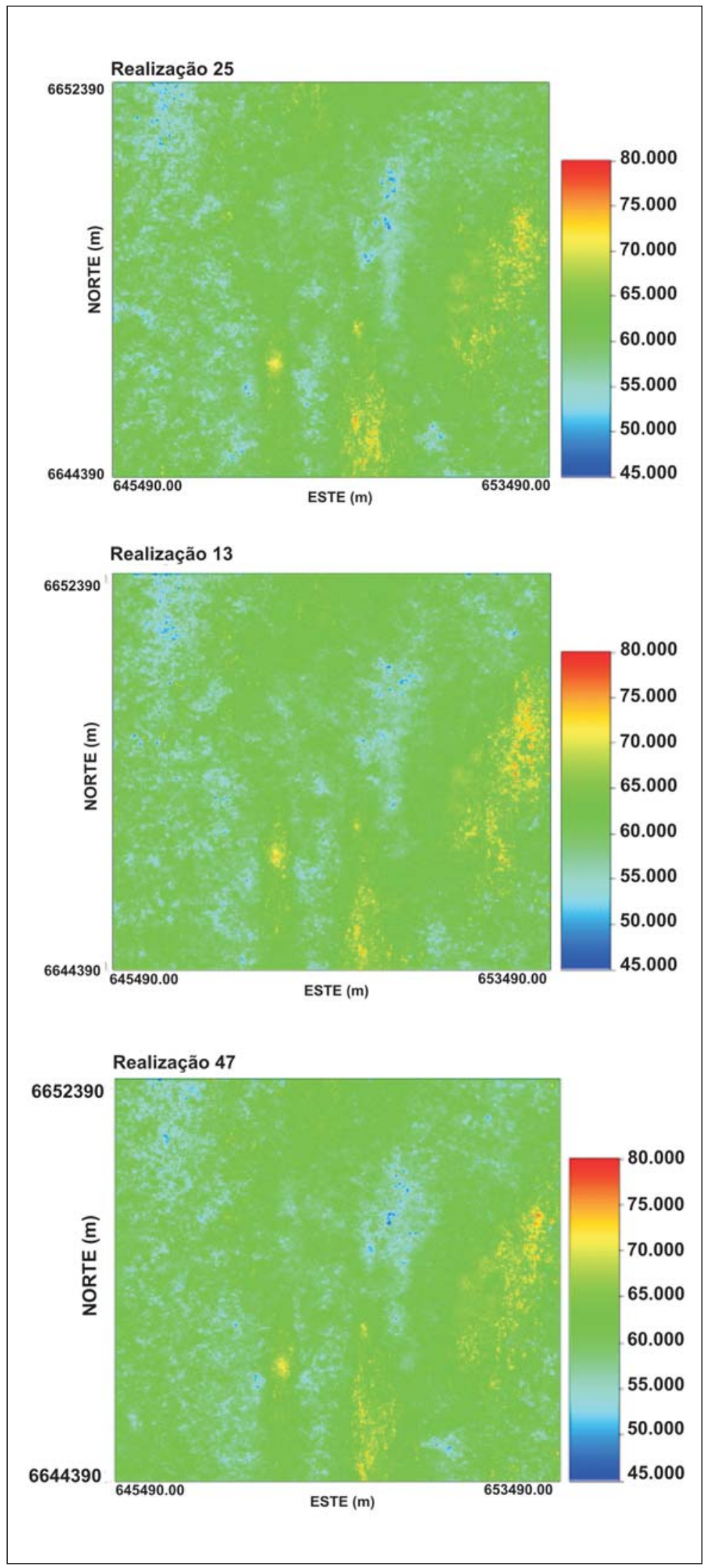

Figura 3 - Três realizações escolhidas aleatoriamente para a variável teor de cinzas. 
área da mina, sendo assim a área minerada poderá ser dividida em lotes de minério. Segundo Valente (1982), as flutuações de teores, existentes à escala diária, semanal, mensal, etc. e determináveis com a relação volume $\mathrm{x}$ variância, irão ser úteis no planejamento da lavra em jazidas não homogêneas.

A metodologia proposta pelo trabalho foi aplicada considerando o projeto de lavra em câmaras e pilares já estabelecidos para a mina em estudo, já que se trata de uma mineração existente, já produzindo carvão, e que será vinculada a uma usina termoelétrica a ser instalada na boca da mina, cujo projeto de viabilidade técnica e econômica foi concluído. O projeto da mina é constituído de 64 painéis de lavra, responsáveis por 25 anos de produção. Para esse estudo, utilizaram-se os painéis 8 e 9 para a análise dos lotes que satisfaçam as condições impostas controlando as flutuações do teor de cinzas. A Figura 4 apresenta os painéis 8 e 9 e as variações locais dos teores de cinza em um modelo simulado.

A Tabela 1 apresenta as áreas que devem ser mineradas para que diferentes volumes de minério sejam produzidos. Essas informações foram obtidas a partir do projeto de lavra da mina subter-

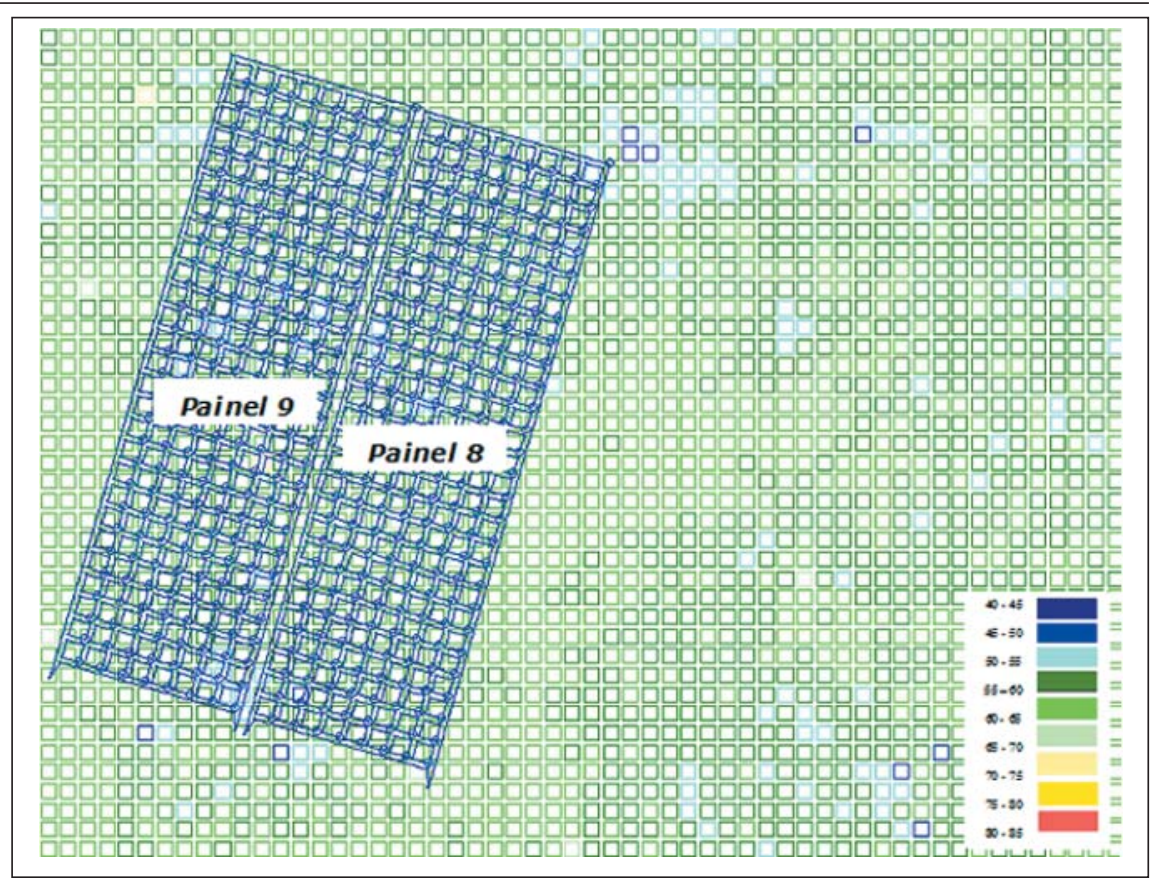

Figura 4 - Visualização de um modelo simulado na área compreendida pelos painéis 8 e 9.

Tabela 1 - Relações entre tempo de produção, área média minerada e tonelagem média de minério produzido por um conjunto mecanizado.

\begin{tabular}{c|c|c}
\hline $\begin{array}{c}\text { Tempo aproximado de } \\
\text { produção }\end{array}$ & $\begin{array}{c}\text { Área minerada } \\
\mathbf{( m}^{\mathbf{2}} \mathbf{)}\end{array}$ & $\begin{array}{c}\text { Minério ROM } \\
\text { produzido }(\mathbf{t})\end{array}$ \\
\hline 4 dias & 2500 & $7.711,25$ \\
\hline 16 dias & 10000 & $30.845,00$ \\
\hline 31 dias & 19600 & $60.456,20$ \\
\hline
\end{tabular}

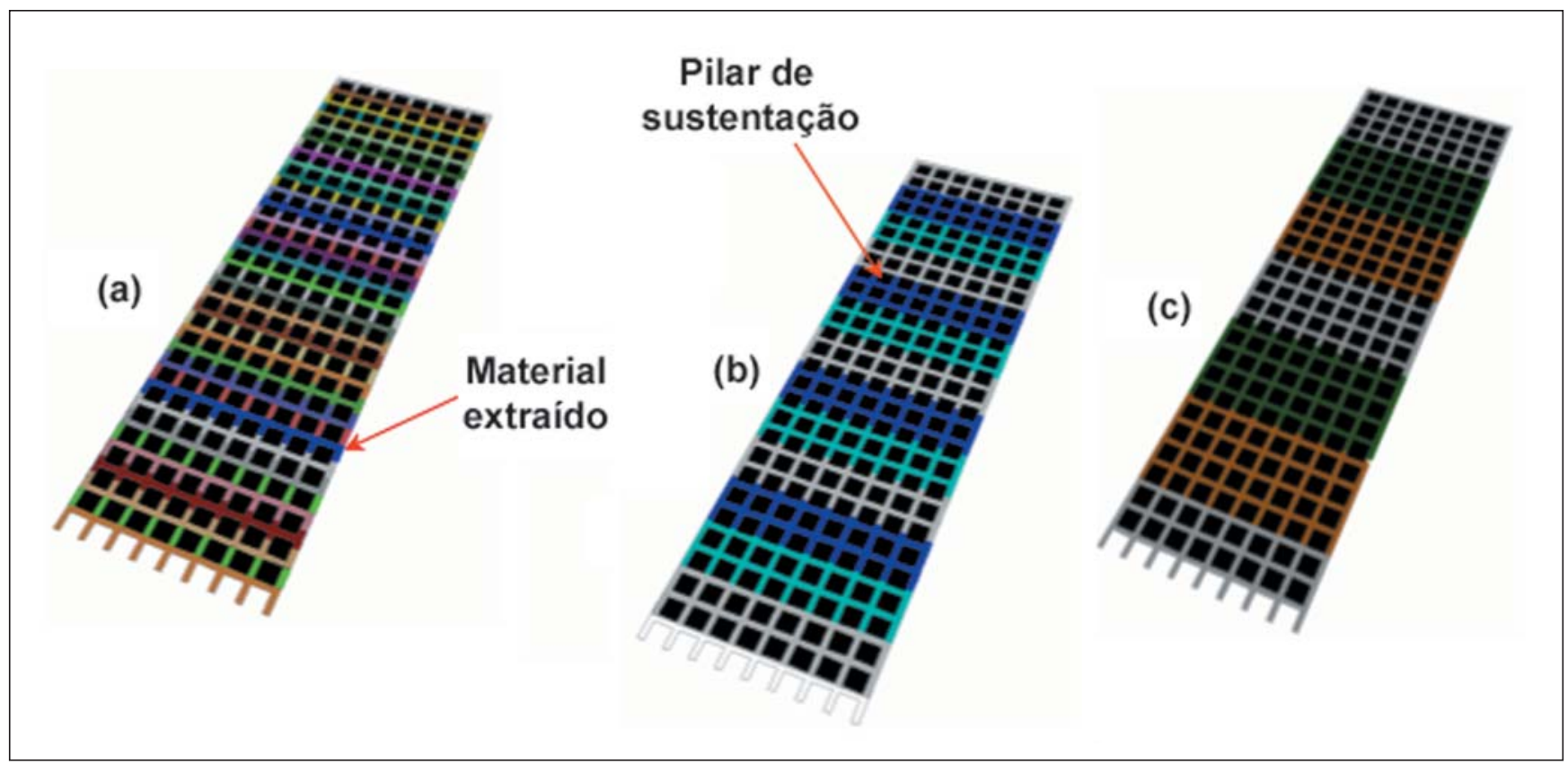

Figura 5 - Painel dividido em lotes de diferentes tamanhos. (a) Lotes de 4 dias de produção; (b) Lotes de 16 dias de produção; (c) lotes de 31 dias de produção. Em cada situação, a mudança de cor representa um lote diferente. 
rânea. A partir dai, é possível fazer a associação entre o volume de um lote constituído de minério lavrado em determinado período/área e a flutuação do teor de cinzas nos cenários selecionados.

Um lote de minério ROM deve ser analisado como o volume realmente extraído no avanço de um conjunto mecanizado em um painel de lavra. A Figura 5 mostra os diferentes tamanhos de lote utilizados na análise, apresentando a adaptação do lote à seqüência de extração do minério.

Com base nos possíveis cenários representados pelas simulações escolhidas anteriormente, foram calculados, para os painéis 8 e 9 , os teores de cinzas variando-se o tamanho do lote. As Figuras 6 e 7 apresentam os gráficos para as flutuações dos teores para os diferentes tamanhos de lote nos painéis 8 e 9 .

Os resultados apresentados nas Figura 6 e 7 mostram que cada um dos modelos simulados apresenta uma resposta diferente para o teor de cinzas em cada um dos lotes. $\mathrm{O}$ aumento do tamanho do lote implica a redução da variabilidade dos teores dos lotes até que se obtenha um tamanho que garanta todos os lotes dentro dos limites especificados. Quanto menor o lote de minério, maior será o risco associado ao teor de cinzas. Esse efeito se dá pela relação volume x variância, onde o aumento do volume implica a redução da variância, uma vez que um número maior de dados é considerado.

O modelo obtido pela média das simulações (E-TYPE) apresenta a suavização dos teores de cinza, já que a variabilidade dos teores obtidos é menor que a dos dados originais e dos modelos gerados por simulação. Esse efeito é semelhante ao que seria obtido por um modelo gerado por krigagem. Note que, para o modelo E-TYPE, lotes de 4 dias de produção seriam suficientes para garantir todos os lotes com teores dentro dos limites especificados, o que poderia resultar em multas contratuais não esperadas, uma vez que a utilização de modelos simulados alerta para a possibilidade de lotes com teores fora dos limites estabelecidos.

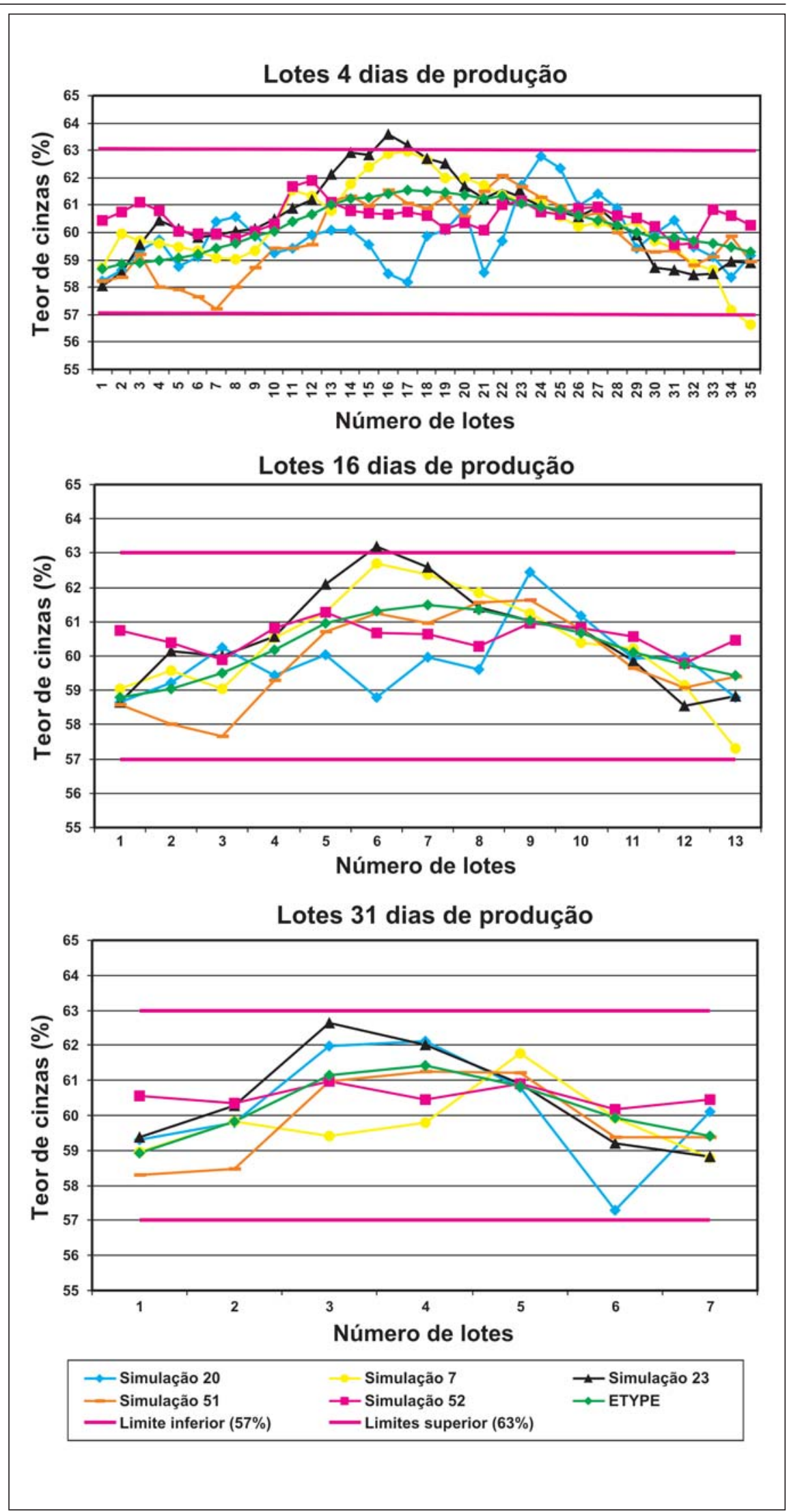

Figura 6 - Flutuação do teor de cinzas obtido a partir da combinação das simulações selecionadas para diferentes tamanhos de lote no painel 8. 


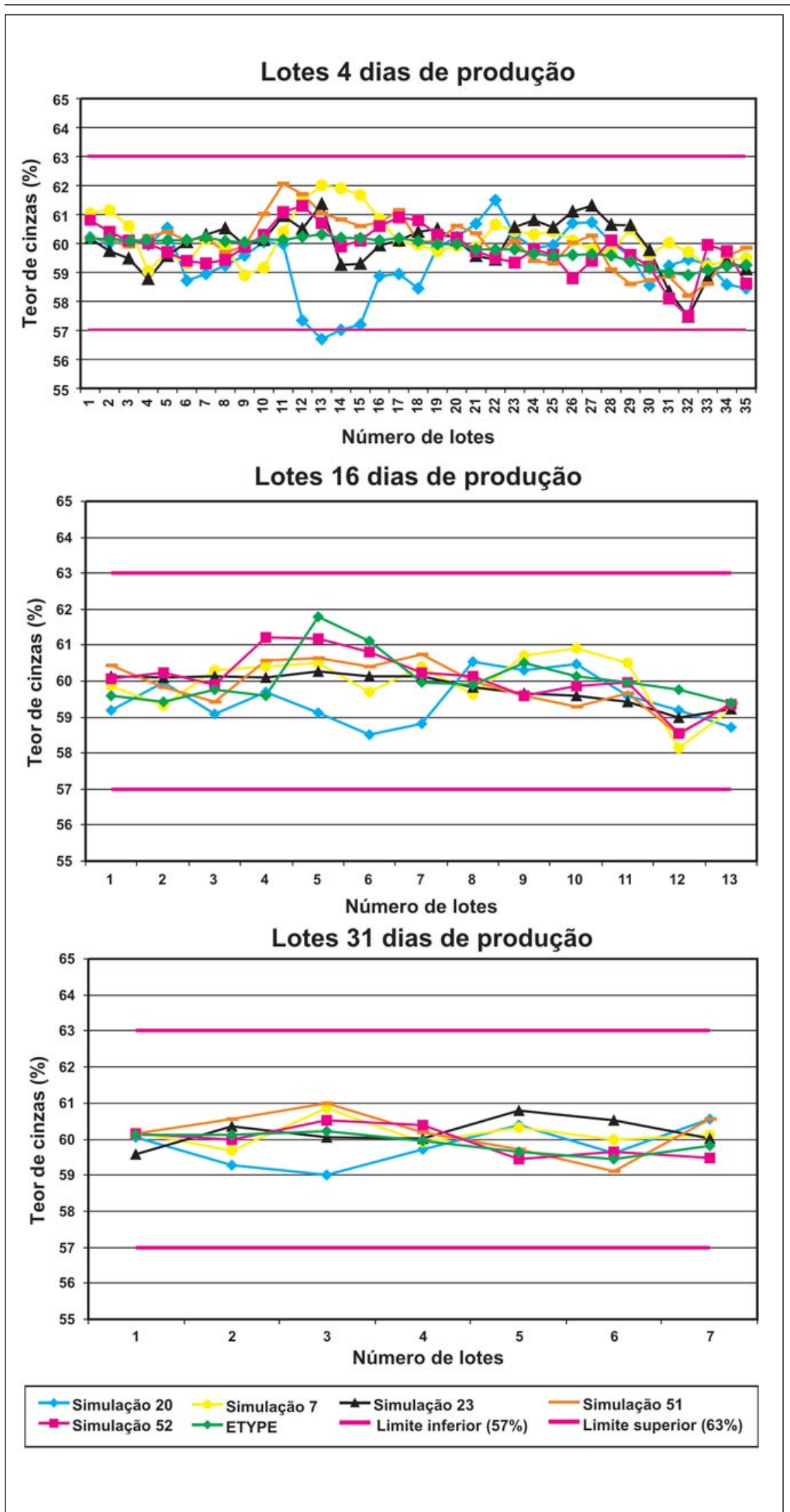

Figura 7 - Flutuação do teor de cinzas obtido a partir da combinação das simulações selecionadas para diferentes tamanhos de lote no painel 9 .
Os gráficos apresentados nas Figuras 6 e 7 mostram a atenuação das oscilações do teor de cinzas conforme 0 aumento do tamanho do lote em ambos os painéis. No entanto, as oscilações em torno do teor de cinzas apresentam comportamentos distintos. Enquanto que o painel 8 apresenta uma tendência de lotes com teores elevados para o centro do painel, inclusive com lotes fora dos limites, o painel 9 apresenta um comportamento regular em torno de $60 \%$ de cinzas para todo o painel. Note, ainda, que o painel 9 atinge $100 \%$ dos lotes controlados, com um volume de lote referente à produção de 10 dias, enquanto que $\mathrm{o}$ painel 8 atinge essa meta apenas com lotes de 31 dias de produção. O painel 9 dividido em lotes de 31 dias de produção permite o controle do teor de cinzas em $60 \% \pm 1 \%$.

\section{Conclusões}

A geração de múltiplos cenários para o depósito permitiu acessar a variabilidade in situ do teor de cinzas. Ao incorporar a incerteza do teor de cinzas na estratégia de controle do minério, na lavra, é possível verificar os possíveis teores que um lote pode assumir.

A utilização de modelos equiprováveis do depósito permite que o controle do minério por lotes incorpore as possíveis flutuações apresentadas por determinada variável no depósito. Assim, a qualidade de um lote de determinado volume pode ser prevista, possibilitando prever as possíveis flutuações do atributo no produto final.

A maior vantagem de incorporar a incerteza associada ao teor de um lote ou volume de minério qualquer é que o destino desse volume, seja ele a usina termoelétrica ou uma usina de beneficiamento, terá o conhecimento da faixa de variação do lote.

\section{Referências bibliográficas}

COSTA, J.F.C.L. Developments in recoverable reserves and ore body 
modeling. Austrália: WH Bryan Mining Geology Research Centre, The University of Queensland, 1997, 333p. (PhD Thesis).

COSTA J.F.C.L., KOPPE, J.C., DIMITRAKOPOULOS, R. ZINGANO, A.C. Incorporating uncertainty associated with prediction of geological attributes in coal mine planning. Proceedings. 27th INTERNATIONAL SYMPOSIUM ON COMPUTER APPLICATIONS IN THE MINERAL INDUSTRIES (APCOM' 1998). London. UK. 1998. p. 470-477.

DEUTSCH, C.V., JOURNEL, A.G. GSLIB: Geostatistical Software Library and
User's Guide. New York: Oxford University Press, 1998. 483p.

GAMBIN, F. Aperfeiçoamento da estratégia de homogeneização de minérios utilizando simulação geoestatística. Universidade Federal do Rio Grande do Sul: Programa de Pós-Graduação em Engenharia de Minas, Metalúrgica e de Materiais (PPGEM), 2001. 96p. (Dissertação de Mestrado).

GOOVAERTS, P. Geostatistics for natural resources evaluation. New York: Oxford University Press, 1997. 483 p.

JOURNEL, A.G. Geostatistics for conditional simulation of ore bodies.
Economic Geology, v. 69, p. 673-687, 1974.

JOURNEL, A. G., HUIJBREGTS, C. J. Mining Geostatistics. London: Academic Press, 1978. $600 \mathrm{p}$.

SCHOFIELD, C.G. Homogenisation/ blending systems design and control for minerals processing. Germany: TransTech Publications, 1980. 236 p.

VALENTE, J.M.G.P. Geomatemática - lições de geoestatística. Ouro Preto: Fundação Gorceix, 1982. v. 6, 323p.

Artigo recebido em 29/09/2004 e aprovado em 06/07/2005.

\section{A Rem já está comemorando os seus 70 anos. Ela agora faz parte das revistas indexadas pela Iniciativa dos Arquivos Abertos.}

\section{PUBLIC KNOWLEDGE PROJECT \\ Open Archives Harvester}

Home > Add an Archive

\section{Add an Archive}

The archive REM - Revista Escola de Minas has been successfully added to our database, and will be indexed shortly. Thank you for your submission.

Back to Home

Home | Search | Archives | Submit Archive | Links | About

(C) 2003-2004 Public Knowledge Project 